\title{
Osteoprotegerin and breast cancer risk by hormone receptor subtype: a nested case- control study in the EPIC cohort
}

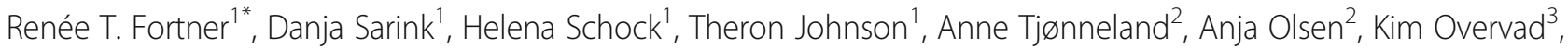
Aurélie Affret ${ }^{4,5}$, Mathilde His ${ }^{4,5}$, Marie-Christine Boutron-Ruault ${ }^{4,5}$, Heiner Boeing ${ }^{6}$, Antonia Trichopoulou ${ }^{7,8}$, Androniki Naska ${ }^{7,8}$, Philippos Orfanos ${ }^{7,8}$, Domenico Palli ${ }^{9}$, Sabina Sieri ${ }^{10}$, Amalia Mattiello ${ }^{11}$, Rosario Tumino ${ }^{12}$, Fulvio Ricceri ${ }^{13,14}$, H. Bas Bueno-de-Mesquita ${ }^{15,16,17}$, Petra H. M. Peeters ${ }^{18,19}$, Carla H. Van Gils ${ }^{18}$, Elisabete Weiderpass ${ }^{20,21,22,23}$, Eiliv Lund ${ }^{20}$, J. Ramón Quirós ${ }^{24}$, Antonio Agudo ${ }^{25}$, Maria-José Sánchez ${ }^{26,27}$, María-Dolores Chirlaque $27,28,29$, Eva Ardanaz ${ }^{27,30,31}$, Miren Dorronsoro ${ }^{32}$, Tim Key ${ }^{33}$, Kay-Tee Khaw ${ }^{34}$, Sabina Rinaldi ${ }^{35}$, Laure Dossus ${ }^{35}$, Marc Gunter ${ }^{35}$, Melissa A. Merritt ${ }^{16}$, Elio Riboli ${ }^{16}$ and Rudolf Kaaks ${ }^{1}$

\begin{abstract}
Background: Circulating osteoprotegerin (OPG), a member of the receptor activator of nuclear factor kappa-B (RANK) axis, may influence breast cancer risk via its role as the decoy receptor for both the RANK ligand (RANKL) and tumor necrosis factor-related apoptosis-inducing ligand (TRAIL). Circulating OPG and breast cancer risk has been examined in only one prior study.

Methods: A case-control study was nested in the European Prospective Investigation into Cancer and Nutrition (EPIC) cohort. A total of 2008 incident invasive breast cancer cases (estrogen receptor (ER)+, $n=1622$; ER-, $n=386$ ), matched 1:1 to controls, were included in the analysis. Women were predominantly postmenopausal at blood collection (77\%); postmenopausal women included users and non-users of postmenopausal hormone therapy (HT). Serum OPG was quantified with an electrochemiluminescence assay. Relative risks (RRs) and 95\% confidence intervals (Cls) were calculated using conditional logistic regression.

Results: The associations between OPG and ER+ and ER- breast cancer differed significantly. Higher concentrations of OPG were associated with increased risk of ER- breast cancer (top vs. bottom tertile RR $=1.93$ [95\% Cl 1.24-3.02]; $p_{\text {trend }}=0.03$ ). We observed a suggestive inverse association for ER+ disease overall and among women premenopausal at blood collection. Results for ER- disease did not differ by menopausal status at blood collection $\left(p_{\text {het }}=0.97\right.$ ), and we observed no heterogeneity by HT use at blood collection ( $p_{\text {het }} \geq 0.43$ ) or age at breast cancer diagnosis ( $p_{\text {het }} \geq 0.30$ ).
\end{abstract}

Conclusions: This study provides the first prospective data on OPG and breast cancer risk by hormone receptor subtype. High circulating OPG may represent a novel risk factor for ER- breast cancer.

Keywords: Breast cancer, Osteoprotegerin, RANK axis, Hormone receptor, Estrogen receptor, Progesterone receptor

\footnotetext{
* Correspondence: r.fortner@dkfz.de

'Division of Cancer Epidemiology, German Cancer Research Center (DKFZ),

Im Neuenheimer Feld 280, D-69120 Heidelberg, Germany

Full list of author information is available at the end of the article
} 


\section{Background}

Osteoprotegerin (OPG) is a homodimeric glycoprotein and a member of the tumor necrosis factor (TNF) receptor superfamily [1]. OPG was first characterized as a negative regulator of bone turnover. Bone homeostasis is maintained by the interplay between the receptor activator of nuclear factor kappa-B (RANK), its soluble activation ligand (RANKL), and OPG. OPG binds RANKL as a decoy receptor, inhibiting the activation of RANK by RANKL and preventing the differentiation of bone marrow precursor (monocyte/macrophage) cells to osteoclasts - cells that are central in the process of bone resorption [2].

Besides bone, OPG is expressed in other tissues, including the stomach, intestines, skin, liver, heart, lung, kidney, and breast. This expression across diverse tissue types indicates that its biologic functions may extend beyond bone metabolism. In relation to breast cancer, OPG was initially investigated as a potential inhibitor of metastasis-related osteolysis [3, 4]. The RANKL inhibitor denosumab acts to reduce skeletal-related events in patients with bone metastases. More recent data show that OPG is also produced in breast tumor cells, and that it can promote tumor growth and metastasis $[5,6]$. In vitro studies suggest that OPG, again acting as a decoy receptor, also binds to TNF-related apoptosisinducing ligand (TRAIL), thereby preventing cancer cell death via apoptosis [7, 8]. Furthermore, OPG can induce cell proliferation and angiogenesis through a variety of cell surface receptors $[5,6]$.

Besides local expression in many tissue types, OPG is present in blood. Circulating OPG has been examined in the context of chronic disease risk, including impaired glucose tolerance and type 2 diabetes [9], vascular calcification, atherosclerosis and cardiovascular disease $[10,11]$, cancer [12], and overall mortality [10]. However, to date, only one prospective study has examined the relationship between circulating OPG and breast cancer risk [12]. This study observed reduced breast cancer risk among women with comparatively high OPG concentrations, but given a small number of incident cases $(n=76)$, risk by tumor subtypes (e.g., by estrogen (ER) and progesterone (PR) receptor status) was not investigated. We provide the first prospective data on OPG and breast cancer risk by hormone receptor status, in a large nested casecontrol study in the European Prospective Investigation into Cancer and Nutrition (EPIC) cohort.

\section{Methods}

The EPIC cohort was designed to identify risk factors for cancer [13]. Briefly, between 1992 and 2000 about 520,000 apparently healthy men and women ( $n=367,993$ women), from 10 European countries (Denmark, France, Germany, Greece, Italy, the Netherlands, Norway, Spain, Sweden, and the United Kingdom), generally between ages 35 and 75 years, enrolled in the study. Detailed dietary, anthropometric, lifestyle, and medical history data were collected via standardized methods. Blood samples were collected according to standardized protocols ( $n=235,607$ women). Samples for this study were stored centrally under liquid nitrogen $\left(-196{ }^{\circ} \mathrm{C}\right)$ at the International Agency for Research on Cancer (IARC), except those from Denmark, which were stored locally at $-150{ }^{\circ} \mathrm{C}$.

Incident cancers were identified through linkages with regional cancer registries except in France, Germany, Greece, and Naples (Italy), where follow-up is conducted by review of health insurance records, contacts with cancer and pathology registries, and/or direct contact with cohort members. Vital status is ascertained through linkages with regional and national mortality registries and active follow-up (Germany and Greece). Details on the identification and verification of incident breast cancer cases and collection of hormone receptor status data were reported previously [14].

\section{Nested case-control study}

Case and control selection has been described previously [15]. Cases and matched controls were women either pre- or postmenopausal at the time of blood collection, with no previous diagnosis of invasive cancer (with the exception of non-melanoma skin cancer) or in situ breast cancer. Premenopausal women included in this study were not using oral contraceptives (OCs), whereas the postmenopausal study population included both hormone therapy (HT) users and non-users. Participants from Sweden were not included in this investigation, given the independent studies on breast cancer risk conducted in those centers.

The end of follow-up for this study was the last date of complete follow-up for both cancer incidence and vital status (range: 2003-2006, depending on the study center). All incident cases with ER status available were included through 2004. After 2004, all newly diagnosed ER- cases were included, and among postmenopausal women an equal number of ER+ cases were randomly selected among cases matching each ER- case for recruitment center.

One control per case was selected among cohort members who donated a blood sample and who were alive and free of cancer (except non-melanoma skin cancer) at the time of invasive breast cancer diagnosis of the index case. Controls were matched to cases on recruitment center, age ( \pm 3 months), menopausal status, HT use, fasting status $(<3,3-6,>6$ hours $)$, and time of day $( \pm 1$ hour $)$ at blood donation. Premenopausal women were also matched for phase of menstrual cycle (early follicular, late follicular, periovulatory, early luteal, midluteal, late luteal). 
A total of 2020 case-control sets were initially selected. After excluding sets in which the case or control was missing the OPG measurement ( $n=7$ sets) or had OPG values identified as outliers ( $n=5$ sets), a total of 2008 case-control sets remained for analysis. PR status was available for a total of $74 \%$ of cases $(n=1480)$.

\section{Within-person reproducibility study}

The EPIC-Heidelberg cohort was recruited between 1994 and 1998. The EPIC-Heidelberg substudy has been described previously [16]. Briefly, between 2010 and 2013, approximately 600 cohort participants (50\% women) provided additional blood samples, with a total of 592 participants providing samples and exposure data at baseline and 14 and 15 years after recruitment. OPG was measured in repeat blood samples from 221 women randomly selected from this population to assess within-person reproducibility over 1 year (between years 14 and 15) and over 14 years (between baseline and year 14) (Additional file 1: Table S1).

\section{Laboratory methods}

Serum OPG concentrations were measured in the Laboratory of the Division of Cancer Epidemiology at the German Cancer Research Center (DKFZ), using an electrochemiluminescence assay (MesoScale Diagnostics, Rockville, MD, USA). Samples from cases and their matched controls were analyzed in the same analytical batch, and laboratory personnel were blinded to the case-control status of the samples. The precision of the laboratory work was monitored by inclusion of blinded pooled quality control (QC) samples (two per batch). Intra-batch coefficients of variation (CVs) were $15 \%$; inter-batch CVs were $17 \%$.

Serum concentrations of estradiol, estrone, testosterone, dehydroepiandrosterone sulfate (DHEAS), sex hormonebinding globulin (SHBG), progesterone, prolactin, and insulin-like growth factor 1 (IGF-1) were available for subsets of the study population and were assessed as covariates and effect modifiers. Laboratory methods have been described previously $[14,15,17,18]$.

\section{Statistical analyses}

OPG was $\log 2$-transformed to obtain an approximately normal distribution; this transformation allows an estimation of the effect of a doubling of biomarker concentration. Outliers were evaluated using the extreme Studentized deviate many-outlier procedure [19].

Spearman correlations were used to evaluate associations between OPG and continuous covariates and endogenous hormones; geometric means of OPG were compared between categories of categorical covariates. These analyses were restricted to controls and adjusted for matching factors. OPG was classified into tertiles based on the distribution in controls. As OPG levels do not vary significantly by menopausal status, tertile cutoff points were calculated based on the overall control population. Conditional logistic regression was used to estimate the relative risk (RRs) and 95\% confidence intervals (CIs). Tests for trend were based on OPG modeled as a continuous variable. OPG concentrations are known to increase with age; therefore, Spearman correlations were used to examine the reproducibility of the relative ranking of study subjects over time, comparing concentrations in samples taken 1 and 14 years apart.

Ages at menarche, menopause, and first full-term pregnancy (FTP), number of FTPs, and body mass index (BMI; $\mathrm{kg} / \mathrm{m}^{2}$ ) were included in the multivariable model. Additional adjustment for lifetime mean alcohol consumption, past oral contraceptive use, breastfeeding, and smoking status did not materially impact the results $\left(\mathrm{RR}_{\log 2}\right.$ change $\left.<10 \%\right)$.

We evaluated heterogeneity by reproductive and lifestyle factors or endogenous hormone levels by comparing models including and excluding interaction terms using the likelihood ratio test (LRT). Tests for interaction were based on continuous, log2-transformed OPG concentrations. We assessed potential heterogeneity by tumor hormone receptor status and age at diagnosis ( $<50$ vs. $50+$ years) by comparing models assuming the same association between OPG and breast cancer in subgroups (e.g., ER+ and ER-) to one assuming different associations by subgroup using the LRT [20]. We examined the possibility of non-linearity non-parametrically with restricted cubic splines [21]. Tests for non-linearity used the LRT, comparing the model with only the linear term to the model with the linear and the cubic spline terms. There was no evidence of deviations from linearity $(p>0.12)$, with the exception of the association between OPG and ER+ breast cancer among women premenopausal at blood collection $(p=0.03)$. Finally, we performed sensitivity analyses after excluding breast cancer cases diagnosed within 2 years of blood collection ( $n=370,18 \%)$ to address potential reverse causation.

All statistical tests were two-tailed and significant at the $p<0.05$ level. SAS 9.3 (SAS Institute Inc., Cary, NC, USA) was used for all statistical analyses.

\section{Results}

A total of 462 (23\%) case-control pairs were premenopausal at blood donation, whereas 1546 pairs were postmenopausal (Table 1). Among postmenopausal women, a total of 755 pairs (49\%) were using exogenous hormones at blood collection. Median age at baseline was $57\left(10^{\text {th }}\right.$ $90^{\text {th }}$ percentiles: 45-64) years, and among cases the median age at diagnosis was $61\left(10^{\text {th }}-90^{\text {th }}\right.$ percentiles: $50-70)$ years. Median time between blood collection and diagnosis was $4.7 \quad\left(10^{\text {th }}-90^{\text {th }}\right.$ percentiles: $\left.1.2-8.1\right)$ 
Table 1 Baseline and case characteristics: EPIC cohort breast cancer nested case-control study

\begin{tabular}{|c|c|c|}
\hline & Cases & Controls \\
\hline Full study population, $n$ & 2008 & 2008 \\
\hline \multicolumn{3}{|c|}{ Baseline characteristics, median $\left(10^{\text {th }}-90^{\text {th }}\right.$ percentiles) or $n(\%)$} \\
\hline Age at blood collection, years & $57(45-64)$ & $57(45-64)$ \\
\hline Age at menarche, years & $13(11-15)$ & $13(11-15)$ \\
\hline Premenopausal & $462(23 \%)$ & $462(23 \%)$ \\
\hline Postmenopausal & $1546(77 \%)$ & $1546(77 \%)$ \\
\hline HT use at blood collection ${ }^{a}$ & $755(49 \%)$ & 755 (49\%) \\
\hline Age at menopause, years ${ }^{a}$ & $50(43-55)$ & $50(43-55)$ \\
\hline Completed term pregnancy & $1695(84 \%)$ & $1733(86 \%)$ \\
\hline Age at first term pregnancy, years & $25(20-31)$ & $24(20-30)$ \\
\hline $\mathrm{BMl}, \mathrm{kg} / \mathrm{m}^{2}$ & $24(21-31)$ & $24(20-30)$ \\
\hline \multicolumn{3}{|l|}{ Case characteristics } \\
\hline ER+ & $1622(81 \%)$ & \\
\hline ER- & $386(19 \%)$ & \\
\hline $\mathrm{ER}+/ \mathrm{PR}+{ }^{\mathrm{c}}$ & $929(63 \%)$ & \\
\hline ER-/PR- & $258(17 \%)$ & \\
\hline Age at diagnosis, years & $61(50-70)$ & \\
\hline $\begin{array}{l}\text { Time between blood donation } \\
\text { and diagnosis, years }\end{array}$ & $4.7(1.2-8.1)$ & \\
\hline \multicolumn{3}{|c|}{ Osteoprotegerin concentrations, $n g / m L$, median $\left(10^{\text {th }}-90^{\text {th }}\right.$ percentiles $)$} \\
\hline & $\begin{array}{l}0.196 \\
(0.138-0.282)\end{array}$ & $\begin{array}{l}0.197 \\
(0.141-0.289)\end{array}$ \\
\hline
\end{tabular}

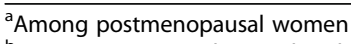

${ }^{\mathrm{b}}$ Among women with completed term pregnancy

'PR status available for $74 \%$ of cases $(n=1480)$; percentages represent percentage of total cases with ER and PR status available

years. Of the 2008 total cases, $81 \%$ were ER+ $(n=1622$; $\mathrm{ER}-, n=386$ ).

Serum OPG concentrations were positively correlated with age $(r=0.29, p<0.01)$. Among premenopausal women, OPG did not vary by menstrual cycle phase ( $p$ $=0.29)$. OPG concentrations did not vary by menopausal status at blood collection $(p=0.31)$. However, among women postmenopausal at blood collection, OPG levels differed between current users and non-users of HT (at time of blood collection; $p=0.01$ ), although the absolute differences were small (adjusted geometric mean concentrations, ng/mL, HT non-users: 0.202 [95\% CI: 0.197-0.207] vs. HT users: 0.210 [0.204-0.216]). Among HT users, OPG levels did not further differ by type of HT (i.e., unopposed vs. opposed estrogens; $p=$ $0.64)$.

OPG concentrations were not correlated with age at menopause, number of FTPs, BMI $\left(\mathrm{kg} / \mathrm{m}^{2}\right)$, or alcohol consumption (g/day), nor did concentrations differ between women with and without completed FTP (data not shown). Higher OPG concentrations were observed in women reporting ever $\mathrm{OC}$ use, as compared to never users (ng/mL, OC use, never: 0.192 [0.188-0.198]; ever OC users: 0.198 [0.193-0.203]; $p=0.02$ ). Among women with additional hormone measurements available ( $n$ : 297-2008) OPG was not correlated $(r<|0.14|)$ with endogenous sex steroid hormones, IGF-I, or prolactin, among either pre- or postmenopausal women, or within strata of postmenopausal HT users and non-users (Additional file 1: Table S2).

We observed significant heterogeneity in the association between OPG and risk of ER+ vs. ER- tumors $\left(p_{\text {het }}=0.02\right) \quad($ Table 2$)$. Higher concentrations of OPG were associated with increased risk of ER- breast cancer (top vs. bottom tertile RR $=1.93$ [95\% CI 1.24-3.02]; $\left.p_{\text {trend }}=0.03\right)$. In contrast, we observed a suggestive inverse association between $\mathrm{OPG}$ and $\mathrm{ER}+$ disease (top vs. bottom tertile $\mathrm{RR}=0.84$ [95\% CI 0.68-1.04]; $p_{\text {trend }}=0.18$ ). The association between OPG and ER- disease did not differ by menopausal status $\left(p_{\text {het }}=0.97\right)$. However, we observed suggestive heterogeneity by menopausal status for ER+ disease ( $p_{\text {het }}=0.05$; premenopausal, $\mathrm{RR}_{\log 2}=0.53$ [0.31-0.88]); postmenopausal, $\mathrm{RR}_{\log 2}=0.97$ [0.75-1.25]; Table 3). However, there was evidence of potential nonlinearity of the association between OPG and ER+ breast cancer among women premenopausal at blood collection $(p=0.03$; Additional file 1: Figure S1), and this association should be interpreted cautiously. We observed no heterogeneity by HT use (among postmenopausal women; $p_{\text {het }} \geq 0.43$ ) or by age at breast cancer diagnosis (age $<50$ vs. $50+; p_{\text {het }} \geq 0.30$; Table 4 ). Results were similar in analyses considering both ER and PR status.

We observed no evidence for effect modification by other reproductive and lifestyle factors (e.g., ever fullterm pregnancy, OC use, age at menopause (postmenopausal women) or by levels of endogenous hormones (e.g., estradiol, progesterone, prolactin; data not shown), with the exception of suggestive heterogeneity by prolactin concentrations for ER- disease (prolactin $<$ median, $\mathrm{RR}=0.78$ [0.23-2.69]; $\geq$ median, $\mathrm{RR}=2.98$ [1.23-7.23]; $\left.p_{\text {het }}=0.05\right)$ and heterogeneity by testosterone concentrations for $\mathrm{ER}+$ disease (testosterone $<$ median, $\mathrm{RR}=0.35$ [0.15-0.79]; $\geq$ median, $\left.\mathrm{RR}=1.05[0.52-2.13] ; p_{\text {het }}=0.04\right)$. Finally, results were similar in sensitivity analyses restricted to women diagnosed $>2$ years after blood collection. OPG demonstrated high within-person reproducibility, in terms of the relative ranking of study participants, over 1 year $(r=0.85)$ and 14 years $(r=0.75)$.

\section{Discussion}

Higher serum osteoprotegerin (OPG) concentrations were associated with an increased risk of ER- breast cancer, and a modest, suggestive reduction in risk of ER+ tumors, in this large investigation. With a total of 2008 breast cancer cases with documented ER status, this is the first large-scale prospective study to address circulating OPG 
Table 2 Circulating concentrations of osteoprotegerin and breast cancer risk by hormone-receptor subtype: EPIC cohort breast cancer nested case-control study

\begin{tabular}{|c|c|c|c|c|c|c|}
\hline \multirow[b]{3}{*}{ Cut points (ng/mL) } & \multicolumn{3}{|l|}{ Tertiles } & \multirow[b]{3}{*}{$p_{\text {trend }}{ }^{a}$} & \multirow[b]{3}{*}{$\mathrm{RR}_{\log 2}{ }^{\mathrm{b}}$} & \multirow[b]{3}{*}{$p_{\text {het }}{ }^{c}$} \\
\hline & 1 & 2 & 3 & & & \\
\hline & $<0.18$ & $0.18-<0.22$ & $\geq 0.22$ & & & \\
\hline \multicolumn{7}{|l|}{ ER+/PR+ } \\
\hline Cases/controls & $342 / 312$ & $297 / 308$ & 290/309 & & & \\
\hline RR (95\% Cl) & Ref. & $0.84(0.65-1.07)$ & $0.81(0.61-1.08)$ & 0.27 & $0.85(0.63-1.14)$ & 0.02 \\
\hline \multicolumn{7}{|l|}{ ER+ } \\
\hline Cases/controls & $559 / 510$ & $519 / 544$ & $544 / 568$ & & & \\
\hline RR (95\% Cl) & Ref. & $0.84(0.70-1.02)$ & $0.84(0.68-1.04)$ & 0.18 & $0.86(0.68-1.08)$ & 0.02 \\
\hline \multicolumn{7}{|l|}{ ER-/PR- } \\
\hline Cases/controls & $82 / 96$ & $78 / 96$ & $98 / 66$ & & & \\
\hline RR (95\% Cl) & Ref. & $1.12(0.68-1.83)$ & $2.39(1.35-4.23)$ & 0.04 & $1.89(1.03-3.47)$ & \\
\hline \multicolumn{7}{|l|}{ ER- } \\
\hline Cases/controls & $139 / 160$ & $117 / 125$ & 130/101 & & & \\
\hline RR $(95 \%$ Cl) & Ref. & $1.22(0.83-1.83)$ & $1.93(1.24-3.02)$ & 0.03 & $1.69(1.05-2.74)$ & \\
\hline
\end{tabular}

and subsequent breast cancer risk by hormone receptor subtype.

Vik et al. reported an inverse association between OPG concentrations and breast cancer risk in a case-cohort study of more than 6000 women and men (median 13.5year follow-up) [12]. This Norwegian investigation included only 76 breast cancer cases and thus could not address risk by hormone receptor status. Most likely, however, the majority of breast cancer cases were ER+, as this is the predominant subtype among European women. The suggestive inverse association between OPG and ER+ breast cancer risk observed in the current study lies in the same direction as in this previous investigation, although the association observed in our study is weaker. In two analyses restricted to $B R C A 1 / 2$ carriers, higher serum OPG concentrations were associated with lower risk mutation site [22] and lower breast cancer risk ( $n=18$ cases) [23]. BRCA1/2 mutation status was not available in our study population, and family history of breast cancer is missing for the majority of participants (64\%). Therefore, we were unable to evaluate OPG and breast cancer risk restricted to a higher risk population in our study. These three investigations used ELISA assays, while we used an electrochemiluminescence assay. Vik [12] and Oden [23] observed starkly different mean/median OPG concentrations in their two study populations (Vik, reported mean concentration: $3.40 \mathrm{ng} / \mathrm{mL}$; Oden, reported median concentration, $95 \mathrm{ng} / \mathrm{mL}$ ). Widschwendter et al. [22] did not directly report mean or median OPG concentration. To date, there is no cross-assay standardization protocol for OPG. Thus, betweenstudy comparisons must rely on the within-study relative ranking of participants.

Prior investigations show high levels of OPG protein or mRNA in a variety of breast cancer cell lines [3, 6, 24-27], with lower levels in primary human mammary epithelial cells [6]. Studies of primary breast tumors also showed variable degrees of OPG protein [3, 6, 24, 28-30] or mRNA expression [30-34]. In larger patient series, immunohistochemical analyses $[24,29,35]$ indicated OPG protein in $40-45 \%$ of invasive primary tumors, an inverse association between OPG expression and tumor grade and stage, and a positive association with ER status $[24,29,30]$. Studies based on mRNA analysis, however, showed a positive [36], a negative [33, 34], or no association [32] between the gene expressions for OPG and ER status. A limited number of studies have examined non-neoplastic mammary tissue. On balance, these investigations observed some level of OPG expression, however, at lower levels than that observed in breast tumor tissue [6, 29, 31, 37]. In a large, multicenter analysis of more than 4500 patients, higher OPG mRNA expression was associated with reduced breast cancer-specific mortality among patients with ER+ tumors $(n=1941)$, but not among patients with ER- disease $(n=649)$ [33]. These observations support a role for OPG in breast tumor development and prognosis, with potential differences between ER- and ER+ disease. 
Table 3 Circulating concentrations of osteoprotegerin and breast cancer risk by menopausal status at blood collection: EPIC cohort breast cancer nested case-control study

\begin{tabular}{|c|c|c|c|c|c|c|}
\hline \multirow[b]{3}{*}{ Cut points (ng/mL) } & \multicolumn{3}{|l|}{ Tertiles } & \multirow[b]{3}{*}{$p_{\text {trend }}{ }^{a}$} & \multirow[b]{3}{*}{$\mathrm{RR}_{\log 2}{ }^{\mathrm{c}}$} & \multirow[b]{3}{*}{$p_{\text {het }}{ }^{\mathrm{d}}$} \\
\hline & 1 & 2 & 3 & & & \\
\hline & $<0.18$ & $0.18-<0.22$ & $\geq 0.22$ & & & \\
\hline \multicolumn{7}{|c|}{ Hormone receptor positive cases } \\
\hline \multicolumn{7}{|c|}{ Premenopausal } \\
\hline \multicolumn{7}{|l|}{$\mathrm{ER}+/ \mathrm{PR}+$} \\
\hline Cases/controls & $168 / 152$ & $61 / 77$ & $24 / 24$ & & & \\
\hline $\mathrm{RR}(95 \% \mathrm{Cl})$ & Ref. & $0.67(0.43-1.04)$ & $0.89(0.42-1.87)$ & 0.07 & $0.58(0.32-1.05)$ & 0.36 \\
\hline \multicolumn{7}{|l|}{$\mathrm{ER}+$} \\
\hline Cases/controls & $236 / 200$ & $79 / 118$ & $37 / 34$ & & & \\
\hline $\mathrm{RR}(95 \% \mathrm{Cl})$ & Ref. & $0.55(0.38-0.81)$ & $0.85(0.47-1.55)$ & $0.01^{\mathrm{b}}$ & $0.53(0.31-0.88)^{b}$ & $0.05^{\mathrm{b}}$ \\
\hline \multicolumn{7}{|l|}{ Postmenopausal } \\
\hline \multicolumn{7}{|l|}{$\mathrm{ER}+/ \mathrm{PR}+$} \\
\hline Cases/controls & $174 / 160$ & $236 / 231$ & $266 / 285$ & & & \\
\hline $\operatorname{RR}(95 \% \mathrm{Cl})$ & Ref. & $0.92(0.68-1.24)$ & $0.85(0.61-1.17)$ & 0.73 & $0.94(0.66-1.33)$ & \\
\hline \multicolumn{7}{|l|}{ ER+ } \\
\hline Cases/controls & $323 / 310$ & $440 / 426$ & $507 / 534$ & & & \\
\hline RR $(95 \% \mathrm{Cl})$ & Ref. & $0.98(0.78-1.22)$ & $0.91(0.72-1.15)$ & 0.79 & $0.97(0.75-1.25)$ & \\
\hline \multicolumn{7}{|c|}{ Hormone receptor negative cases } \\
\hline \multicolumn{7}{|l|}{ Premenopausal } \\
\hline \multicolumn{7}{|l|}{ ER-/PR- } \\
\hline Cases/controls & $35 / 44$ & $18 / 17$ & $14 / 6$ & & & \\
\hline RR $(95 \%$ Cl) & Ref. & $1.60(0.57-4.44)$ & $3.77(0.86-16.4)$ & 0.25 & $2.01(0.60-6.70)$ & 0.87 \\
\hline \multicolumn{7}{|l|}{ ER- } \\
\hline Cases/controls & $59 / 70$ & $30 / 30$ & $21 / 10$ & & & \\
\hline RR (95\% Cl) & Ref. & $1.42(0.67-2.99)$ & $3.21(1.17-8.85)$ & 0.26 & $1.63(0.70-3.84)$ & 0.97 \\
\hline \multicolumn{7}{|l|}{ Postmenopausal } \\
\hline \multicolumn{7}{|l|}{ ER-/PR- } \\
\hline Cases/controls & $47 / 52$ & $60 / 79$ & $84 / 60$ & & & \\
\hline RR $(95 \%$ Cl) & Ref. & $1.02(0.55-1.89)$ & $2.03(1.03-3.98)$ & 0.14 & $1.76(0.82-3.77)$ & \\
\hline \multicolumn{7}{|l|}{ ER- } \\
\hline Cases/controls & $80 / 90$ & $87 / 95$ & 109/91 & 0.12 & $1.62(0.88-2.96)$ & \\
\hline RR $(95 \%$ Cl) & Ref. & $1.14(0.68-1.90)$ & $1.60(0.95-2.69)$ & & & \\
\hline
\end{tabular}

Conditional logistic regression models adjusted for ages at menarche $(\leq 12,13,14, \geq 15$, missing), menopause $(<44,44-47,48-50,51-52,53-54, \geq 55$, missing), first full-term pregnancy (no FTP, $<25,25-30, \geq 30$, missing), number of full-term pregnancies $\left(0,1,2, \geq 3\right.$, missing), and BMI (kg/m ${ }^{2}$, continuous)

${ }^{\mathrm{a}} p_{\text {trend }}$ based on log2-transformed continuous variable

${ }^{b}$ Evidence of non-linear association, $p=0.03$; see Additional file 1: Figure S1

${ }^{\mathrm{c}} \mathrm{RR}$ for a one-unit change in log2-transformed OPG

${ }^{d} p_{\text {heterogeneity }}$ comparing women premenopausal to postmenopausal at blood collection based on RRlog2; among postmenopausal women, results did not differ by HT use at blood collection $(p \geq 0.43)$

We observed increased risk of ER- (and ER-/PR-) breast cancer among women with higher serum OPG concentrations. OPG binding to TRAIL represents one key mechanism through which OPG could promote breast tumor development, particularly of ER- tumors $[8,38]$. TRAIL is highly homologous to tumor necrosis factors (TNFs), and induces apoptosis through specific
TRAIL receptors in a diverse range of cell lines, and preferentially in cancer cells [39]. Analyses in breast cancer cell lines have shown that triple-negative cells (i.e., ER-/PR-/HER2-) are especially sensitive to TRAILinduced apoptosis, whereas sensitivity to TRAIL varies across different HER2+ cell lines, and is systematically absent among ER+ cells [7]. Our study population 
Table 4 Circulating concentrations of osteoprotegerin and breast cancer risk by age at diagnosis: EPIC cohort breast cancer nested case-control study

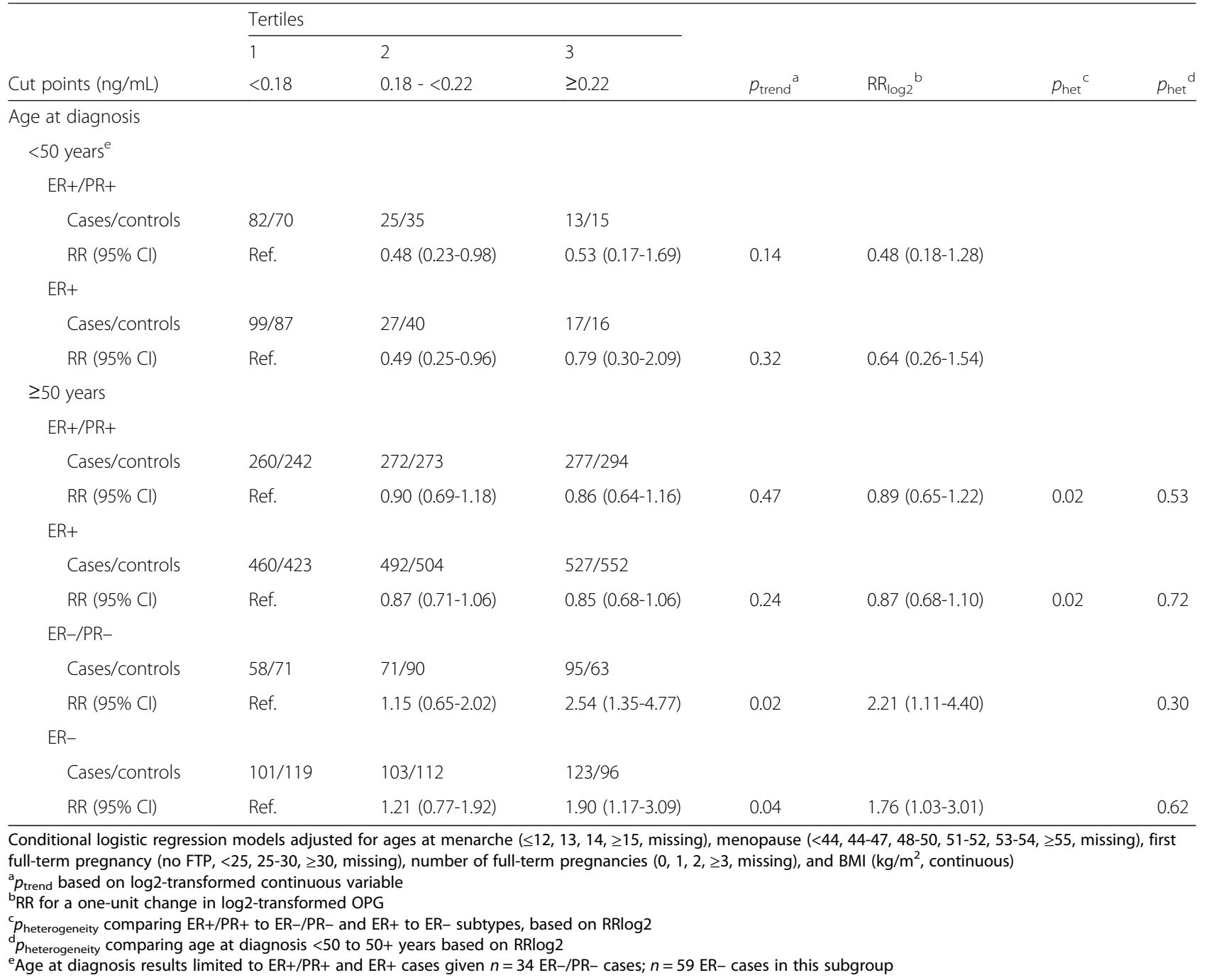

included only 58 triple-negative cases, and we observed no association in this subgroup. We observed a stronger association between OPG and ER- breast cancer risk among women with relatively high circulating prolactin concentrations. Prolactin inhibits TRAIL-induced apoptosis in hormone (androgen)-insensitive PC3 prostate cancer cells [40]. To our knowledge there are no data on prolactin and TRAIL in breast cancer; however, prolactin inhibition has been shown to increase apoptosis in breast cancer cell lines [41], and prolactin interferes with the apoptotic effect of cisplatin chemotherapy [42].

We observed a suggestive inverse association between OPG and ER+ breast cancer. OPG may reduce breast tumor development through binding to RANKL. In addition to regulating bone turnover, RANK and RANKL mediate progesterone- and prolactin-induced changes in the mammary gland, including the expansion of mammary epithelial stem cells [43], proliferation of the mammary epithelium $[44,45]$, and the development of a lactating mammary gland during pregnancy [46]. Furthermore, experimental animal studies have demonstrated that increased expression of RANKL in PR+ luminal epithelial cells, following autocrine and paracrine stimulation of RANK signaling in both receptor positive and negative epithelial cells, is a mechanism mediating progestin-driven mammary carcinogenesis [43, 44, 47, 48]. Circulating OPG may modulate these effects, with one investigation showing increased mammary epithelial proliferation after intravenous administration of soluble RANKL (sRANKL), and inhibition of proliferation by the administration of OPG, in an animal model [44]; in vitro investigations of administered RANKL and OPG in human breast tumor samples show similar results [49]. It is conceivable that OPG inhibits the development of $\mathrm{ER}+/ \mathrm{PR}+$ breast tumors 
by interfering with the growth-promoting effects of RANKL, which depend on PR-mediated local synthesis.

Breast cancer risk increases with higher lifetime number of menstrual cycles, an indicator for cumulative exposure to luteal phase progesterone levels, and is also increased among postmenopausal women using combined estrogenplus-progestin HT [50-52]. Interestingly, RANKL expression in both normal and malignant breast tissue is also increased during the luteal phase of the menstrual cycle [53] and in combined HT users [54]. We observed no indication that the association of serum OPG concentrations with breast cancer risk varied between tumors diagnosed before or after age 50 (the median age at menopause in EPIC), by age at menopause, or between users and nonusers of HT.

While several tissue types produce OPG, bone marrow cells and vascular endothelial cells may be the predominant sources of circulating OPG [55-57]. Estrogens, vitamin D3, and growth hormone promote OPG synthesis in vitro (e.g., by osteoblasts) [55, 58, 59]. Limited cross-sectional data in women support no, or only modest, associations between circulating hormones (e.g., estradiol [60], progesterone [22]) and OPG in healthy women. As in other recent studies [22, 61], we observed no systematic variation of serum OPG concentration with phase of menstrual cycle or with menopausal status (after adjustment for age at blood collection) [62], and a gradual rise of OPG levels with increasing age [58, 62, 63]. Prior studies provide mixed results on whether postmenopausal HT use is associated with OPG [64-66]. We observed somewhat higher OPG concentrations among postmenopausal women using HT, with no differences by HT type (i.e., opposed vs. unopposed estrogens). In subgroup analyses, where additional measurements of endogenous hormones were available, we observed no correlations between OPG and DHEAS, androstenedione, testosterone, estradiol, IGF-I, or prolactin.

\section{Conclusions}

In summary, recent research has revealed intriguing parallels in the roles for OPG and the RANK/RANKL axis in bone metabolism and in mammary gland physiology. Our large-scale investigation is the first to document potentially diverse associations of OPG with risks of ER- or ER+ breast cancer. There is increasing interest in denosumab a humanized antibody that blocks RANKL signaling, which is used routinely to treat osteoporosis - as a drug for preventing breast cancer recurrence among women with early stage breast cancer and primary prevention in high risk women [67]. Although the role of OPG in breast cancer is complex, due to its possible interactions with both TRAIL and RANKL, our data may provide indirect insight into the possible benefits or risks potentially associated with treatments targeting the RANK/RANKL system.

\section{Additional file}

Additional file 1: Table S1. Characteristics of the within-person reproducibility sample $(n=221)$ at baseline (1994-1998) and follow-up (2000-2003). Table S2. Correlations between OPG and select hormones among controls: EPIC cohort nested case-control study. Figure S1. Evidence of potential non-linearity of the association between OPG and ER+ breast cancer among women premenopausal at blood collection from spline regression model: EPIC cohort nested case-control study. (DOCX 84 kb)

\begin{abstract}
Abbreviations
BMI: Body mass index; Cl: Confidence interval; CV: Coefficient of variation; EPIC: European Prospective Investigation into Cancer and Nutrition; ER: Estrogen receptor; FTP: Full-term pregnancy; HT: Hormone therapy; IARC: International Agency for Research on Cancer; LRT: Likelihood ratio test; OC: Oral contraceptive; OPG: Osteoprotegerin; PR: Progesterone receptor; QC: Quality control; RANK: Receptor activator of nuclear factor kappa-B; RANKL: Receptor activator of nuclear factor kappa-B ligand; RR: Relative risk; sRANKL: Soluble RANKL; TNF: Tumor necrosis factor; TRAIL: TNF-related apoptosis-inducing ligand
\end{abstract}

\section{Acknowledgements}

Not applicable.

\section{Funding}

This project was funded by research grant 111454 from the Deutsche Kresbshilfe. RT Fortner was supported by a Marie Curie International Incoming Fellowship of the European Commission's Seventh Framework Programme (MC-IIF-623984). The coordination of EPIC is financially supported by the European Commission (DG-SANCO) and the International Agency for Research on Cancer. The national cohorts are supported by the Danish Cancer Society (Denmark); Ligue Contre le Cancer, Institut Gustave Roussy, Mutuelle Générale de l'Education Nationale, and Institut National de la Santé et de la Recherche Médicale (INSERM) (France); German Cancer Aid, German Cancer Research Center (DKFZ), Federal Ministry of Education and Research (BMBF), Deutsche Krebshilfe, Deutsches Krebsforschungszentrum, and Federal Ministry of Education and Research (Germany); the Hellenic Health Foundation (Greece); Associazione Italiana per la Ricerca sul Cancro-AIRC-Italy and the National Research Council (Italy); the Dutch Ministry of Public Health, Welfare and Sports (WWS), Netherlands Cancer Registry (NKR), LK Research Funds, Dutch Prevention Funds, Dutch ZON (Zorg Onderzoek Nederland), World Cancer Research Fund (WCRF), and Statistics Netherlands (The Netherlands); ERC-2009-AdG 232997 and Nordforsk, Nordic Centre of Excellence programme on Food, Nutrition and Health (Norway); Health Research Fund (FIS), PI13/00061 to Granada, PI13/01162 to EPIC-Murcia, Regional Governments of Andalucía, Asturias, Basque Country, Murcia, and Navarra, and ISCIII RETIC (RD06/0020) (Spain); the Swedish Cancer Society, Swedish Research Council, and County Councils of Skåne and Västerbotten (Sweden); and Cancer Research UK (14136 to EPIC-Norfolk; C570/A16491 and C8221/A19170 to EPIC-Oxford), and the Medical Research Council (1000143 to EPIC-Norfolk, MR/M012190/1 to EPIC-Oxford) (UK).

\section{Availability of data and material}

For information on how to submit an application for gaining access to EPIC data and/or biospecimens, please follow the instructions at http://epic.iarc.fr/ access/index.php.

\section{Authors' contributions}

RTF and RK designed the study and wrote the manuscript. TJ performed the laboratory analyses. All authors contributed to acquisition of data or analysis and interpretation of data. DS and RTF analyzed the data. All authors critically revised and approved the manuscript.

\section{Competing interests}

The authors declare that they have no competing interests.

Consent for publication

Not applicable. 


\section{Ethics approval and consent to participate}

This project was approved by the International Agency for Research on Cancer (IARC) Ethics Committee (Project No. 12-42) and the University of Heidelberg Ethics Commission (Project No. S311/2014). The EPIC study protocol was approved by the ethical committees of IARC and the participating centers. All participants provided informed consent.

\section{Author details}

'Division of Cancer Epidemiology, German Cancer Research Center (DKFZ), Im Neuenheimer Feld 280, D-69120 Heidelberg, Germany. ${ }^{2}$ Diet, Genes and Environment, Danish Cancer Society Research Center, Copenhagen, Denmark. ${ }^{3}$ Section for Epidemiology, Department of Public Health, Aarhus University, Aarhus, Denmark. ${ }^{4}$ Université Paris-Saclay, Université Paris-Sud, UVSQ, CESP, INSERM, Villejuif, France. ${ }^{5}$ Gustave Roussy, F-94805 Villejuif, France. ${ }^{6}$ Department of Epidemiology, German Institute of Human Nutrition Potsdam-Rehbruecke, Nuthetal, Germany. ${ }^{7}$ Hellenic Health Foundation, Athens, Greece. ${ }^{8}$ WHO Collaborating Center for Nutrition and Health, Unit of Nutritional Epidemiology and Nutrition in Public Health, Department of Hygiene, Epidemiology and Medical Statistics, University of Athens Medical School, Athens, Greece. ${ }^{9}$ Cancer Risk Factors and Life-Style Epidemiology Unit, Cancer Research and Prevention Institute - ISPO, Florence, Italy. ${ }^{10}$ Epidemiology and Prevention Unit, Department of Preventive \& Predictive Medicine Fondazione IRCCS Istituto Nazionale dei Tumori, Milan, Italy. ${ }^{11}$ Dipartimento di Medicina Clinica e Chirurgia, Federico II University, Naples, Italy. ${ }^{12}$ Cancer Registry and Histopathology Unit, "Civic - M.p.Arezzo" Hospital, ASP Ragusa, Italy. ${ }^{13}$ Unit of Epidemiology, Regional Health Service ASL TO3, Grugliasco (TO), Italy. ${ }^{14}$ Unit of Cancer Epidemiology, Department of Medical Sciences, University of Turin, Turin, Italy. ${ }^{15}$ Department for Determinants of Chronic Diseases (DCD), National Institute for Public Health and the Environment (RIVM), Bilthoven, The Netherlands. ${ }^{16}$ Department of Epidemiology and Biostatistics, School of Public Health, Imperial College London, London, UK. ${ }^{17}$ Department of Social \& Preventive Medicine, Faculty of Medicine, University of Malaya, Kuala Lumpur, Malaysia. ${ }^{18}$ Department of Epidemiology, Julius Center for Health Sciences and Primary Care, University Medical Center Utrecht, Utrecht, Netherlands. ${ }^{19}$ MRC-PHE Centre for Environment and Health, Department of Epidemiology and Biostatistics, School of Public Health, Imperial College, London, UK. ${ }^{20}$ Department of Community Medicine, Faculty of Health Sciences, University of Tromsø, The Arctic University of Norway, Tromsø, Norway. ${ }^{21}$ Department of Research, Cancer Registry of Norway, Institute of Population-Based Cancer Research, Oslo, Norway. ${ }^{22}$ Department of Medical Epidemiology and Biostatistics, Karolinska Institutet, Stockholm, Sweden. ${ }^{23}$ Genetic Epidemiology Group, Folkhälsan Research Center, Helsinki, Finland. ${ }^{24}$ Public Health Directorate, Asturias, Spain. ${ }^{25}$ Unit of Nutrition and Cancer. Cancer Epidemiology Research Program. Catalan Institute of Oncology-IDIBELL. L'Hospitalet de Llobregat, Barcelona, Spain. ${ }^{26}$ Escuela Andaluza de Salud Pública. Instituto de Investigación Biosanitaria ibs. GRANADA. Hospitales Universitarios de Granada/Universidad de Granada, Granada, Spain. ${ }^{27}$ CIBER de Epidemiología y Salud Pública (CIBERESP), Madrid, Spain. ${ }^{28}$ Department of Epidemiology, Regional Health Council, IMIB-Arrixaca, Murcia, Spain. ${ }^{29}$ Department of Health and Social Sciences, Universidad de Murcia, Murcia, Spain. ${ }^{30}$ Navarra Public Health Institute, Pamplona, Spain. ${ }^{31}$ IdiSNA, Navarra Institute for Health Research, Pamplona, Spain. ${ }^{32}$ Public Health Direction and Biodonostia Research Institute CIBERESP, Basque Regional Health Department, San Sebastian, Spain. ${ }^{33}$ Nuffield Department of Population Health, University of Oxford, Oxford, UK. ${ }^{34}$ Cancer Epidemiology Unit, University of Cambridge, Cambridge, UK. ${ }^{35}$ International Agency for Research on Cancer, Lyon, France.

Received: 6 September 2016 Accepted: 10 January 2017 Published online: 08 February 2017

\section{References}

1. Simonet WS, Lacey DL, Dunstan CR, Kelley M, Chang MS, Lüthy R, Nguyen $H Q$, Wooden S, Bennett L, Boone T, et al. Osteoprotegerin: a novel secreted protein involved in the regulation of bone density. Cell. 1997; 89(2):309-19.

2. Boyle WJ, Simonet WS, Lacey DL. Osteoclast differentiation and activation. Nature. 2003:423(6937):337-42.

3. Thomas RJ, Guise TA, Yin JJ, Elliott J, Horwood NJ, Martin TJ, Gillespie MT. Breast cancer cells interact with osteoblasts to support osteoclast formation. Endocrinology. 1999;140(10):4451-8.
4. Chikatsu N, Takeuchi Y, Tamura Y, Fukumoto S, Yano K, Tsuda E, Ogata E, Fujita T. Interactions between cancer and bone marrow cells induce osteoclast differentiation factor expression and osteoclast-like cell formation in vitro. Biochem Biophys Res Commun. 2000;267(2):632-7.

5. Weichhaus M, Chung ST, Connelly L. Osteoprotegerin in breast cancer: beyond bone remodeling. Mol Cancer. 2015;14:117.

6. Goswami S, Sharma-Walia N. Osteoprotegerin secreted by inflammatory and invasive breast cancer cells induces aneuploidy, cell proliferation and angiogenesis. BMC Cancer. 2015;15:935.

7. Rahman M, Pumphrey JG, Lipkowitz S. The TRAIL to targeted therapy of breast cancer. Adv Cancer Res. 2009;103:43-73.

8. Farooqi AA, Fayyaz S, Tahir M, Iqbal MJ, Bhatti S. Breast cancer proteome takes more than two to tango on TRAlL: beat them at their own game. J Membr Biol. 2012;245(12):763-77.

9. Niu Y, Yang Z, Li X, Zhang W, Lu S, Zhang H, Chen X, Zhu L, Xing Y, Ning G, et al. Association of osteoprotegerin with impaired glucose regulation and microalbuminuria: the REACTION study. BMC Endocr Disord. 2015;15:75.

10. Vik A, Mathiesen EB, Brox J, Wilsgaard T, Njølstad I, Jørgensen L, Hansen J-B. Serum osteoprotegerin is a predictor for incident cardiovascular disease and mortality in a general population: the Tromsø study. J Thromb Haemost. 2011;9(4):638-44.

11. Perez de Ciriza C, Lawrie A, Varo N. Osteoprotegerin in cardiometabolic disorders. Int J Endocrinol. 2015;2015:564934.

12. Vik A, Brodin EE, Mathiesen EB, Brox J, Jorgensen L, Njolstad I, Braekkan SK, Hansen JB. Serum osteoprotegerin and future risk of cancer and cancerrelated mortality in the general population: the Tromso study. Eur J Epidemiol. 2015;30(3):219-30.

13. Riboli E. Nutrition and cancer: background and rationale of the European Prospective Investigation into Cancer and Nutrition (EPIC). Ann Oncol. 1992;3(10):783-91.

14. James RE, Lukanova A, Dossus L, Becker S, Rinaldi S, Tjønneland A, Olsen A, Overvad K, Mesrine S, Engel P, et al. Postmenopausal serum sex steroids and risk of hormone receptor-positive and -negative breast cancer: a nested case-control study. Cancer Prev Res. 2011;4(10):1626-35.

15. Tikk K, Sookthai D, Johnson T, Rinaldi S, Romieu I, Tjonneland A, Olsen A, Overvad K, Clavel-Chapelon F, Baglietto L, et al. Circulating prolactin and breast cancer risk among pre- and postmenopausal women in the EPIC cohort. Ann Oncol. 2014;25(7):1422-8.

16. Barth SD, Schulze JJ, Kuhn T, Raschke E, Husing A, Johnson T, Kaaks R, Olek $\mathrm{S}$. Treg-mediated immune tolerance and the risk of solid cancers: findings from EPIC-Heidelberg. J Natl Cancer Inst. 2015;107(11):dvj224.

17. Kaaks R, Tikk K, Sookthai D, Schock H, Johnson T, Tjønneland A, Olsen A, Overvad K, Clavel-Chapelon F, Dossus L, et al. Premenopausal serum sex hormone levels in relation to breast cancer risk, overall and by hormone receptor status-results from the EPIC cohort. Int J Cancer. 2014;134(8):1947-57.

18. Kaaks R, Johnson T, Tikk K, Sookthai D, Tjonneland A, Roswall N, Overvad K, Clavel-Chapelon F, Boutron-Ruault MC, Dossus L, et al. Insulin-like growth factor I and risk of breast cancer by age and hormone receptor status-a prospective study within the EPIC cohort. Int J Cancer. 2014;134(11):2683-90.

19. Rosner B. Percentage points for a generalized ESD many-outlier procedure. Technometrics. 1983;25(2):165-72.

20. Wang M, Spiegelman D, Kuchiba A, Lochhead P, Kim S, Chan AT, Poole EM, Tamimi R, Tworoger SS, Giovannucci E, et al. Statistical methods for studying disease subtype heterogeneity. Stat Med. 2016;35(5):782-800.

21. Durrleman S, Simon R. Flexible regression models with cubic splines. Stat Med. 1989;8(5):551-61.

22. Widschwendter M, Burnell M, Fraser L, Rosenthal AN, Philpott S, Reisel D, Dubeau L, Cline M, Pan Y, Yi PC, et al. Osteoprotegerin (OPG), the endogenous inhibitor of receptor activator of NF-kappaB ligand (RANKL), is dysregulated in BRCA mutation carriers. EBioMedicine. 2015;2(10):1331-9.

23. Oden $L$, Akbari M, Zaman T, Singer CF, Sun P, Narod SA, Salmena L, Kotsopoulos J. Plasma osteoprotegerin and breast cancer risk in BRCA1 and BRCA2 mutation carriers. Oncotarget. 2016;7(52):86687-94.

24. Holen I, Cross SS, Neville-Webbe HL, Cross NA, Balasubramanian SP, Croucher PI, Evans CA, Lippitt JM, Coleman RE, Eaton CL. Osteoprotegerin (OPG) expression by breast cancer cells in vitro and breast tumours in vivo-a role in tumour cell survival? Breast Cancer Res Treat. 2005;92(3):207-15.

25. Schubert A, Schulz H, Emons G, Grundker C. Expression of osteoprotegerin and receptor activator of nuclear factor-kappaB ligand (RANKL) in HCC70 breast cancer cells and effects of treatment with gonadotropin-releasing hormone on RANKL expression. Gynecol Endocrinol. 2008;24(6):331-8. 
26. Owen $S, Y e L$, Sanders AJ, Mason MD, Jiang WG. Expression profile of receptor activator of nuclear-KB (RANK), RANK ligand (RANKL) and osteoprotegerin (OPG) in breast cancer. Anticancer Res. 2013;33(1):199-206.

27. Tan KB, Harrop J, Reddy M, Young P, Terrett J, Emery J, Moore G, Truneh A. Characterization of a novel TNF-like ligand and recently described TNF ligand and TNF receptor superfamily genes and their constitutive and inducible expression in hematopoietic and non-hematopoietic cells. Gene. 1997;204(1-2):35-46.

28. Bhatia P, Sanders MM, Hansen MF. Expression of receptor activator of nuclear factor-kappaB ligand is inversely correlated with metastatic phenotype in breast carcinoma. Clin Cancer Res. 2005;11:162-5.

29. Van Poznak C, Cross SS, Saggese M, Hudis C, Panageas KS, Norton L, Coleman RE, Holen I. Expression of osteoprotegerin (OPG), TNF related apoptosis inducing ligand (TRAIL), and receptor activator of nuclear factor kappaB ligand (RANKL) in human breast tumours. J Clin Pathol. 2006;59(1):56-63.

30. Cross SS, Harrison RF, Balasubramanian SP, Lippitt JM, Evans CA, Reed MW, Holen I. Expression of receptor activator of nuclear factor kappabeta ligand (RANKL) and tumour necrosis factor related, apoptosis inducing ligand (TRAIL) in breast cancer, and their relations with osteoprotegerin, oestrogen receptor, and clinicopathological variables. J Clin Pathol. 2006;59(7):716-20

31. Reinholz MM, Iturria SJ, Ingle JN, Roche PC. Differential gene expression of TGF-beta family members and osteopontin in breast tumor tissue: analysis by real-time quantitative PCR. Breast Cancer Res Treat. 2002;74(3):255-69.

32. Santini D, Schiavon G, Vincenzi B, Gaeta L, Pantano F, Russo A, Ortega C, Porta C, Galluzzo S, Armento G, et al. Receptor activator of NF-kB (RANK) expression in primary tumors associates with bone metastasis occurrence in breast cancer patients. PLoS One. 2011;6(4):e19234.

33. Sanger N, Ruckhaberle E, Bianchini G, Heinrich T, Milde-Langosch K, Muller V, Rody A, Solomayer EF, Fehm T, Holtrich U, et al. OPG and PgR show similar cohort specific effects as prognostic factors in ER positive breast cancer. Mol Oncol. 2014;8(7):1196-207.

34. Weichhaus M, Segaran P, Renaud A, Geerts D, Connelly L. Osteoprotegerin expression in triple-negative breast cancer cells promotes metastasis. Cancer Med. 2014;3(5):1112-25.

35. Park HS, Lee A, Chae BJ, Bae JS, Song BJ, Jung SS. Expression of receptor activator of nuclear factor kappa-B as a poor prognostic marker in breast cancer. J Surg Oncol. 2014;110(7):807-12.

36. Fradet A, Sorel H, Bouazza L, Goehrig D, Depalle B, Bellahcene A, Castronovo V, Follet $\mathrm{H}$, Descotes $\mathrm{F}$, Aubin JE, et al. Dual function of ERRalpha in breast cancer and bone metastasis formation: implication of VEGF and osteoprotegerin. Cancer Res. 2011;71(17):5728-38.

37. Yang WT, Lewis MT, Hess K, Wong H, Tsimelzon A, Karadag N, Cairo M, Wei C, Meric-Bernstam F, Brown P, et al. Decreased TGFbeta signaling and increased COX2 expression in high risk women with increased mammographic breast density. Breast Cancer Res Treat. 2010;119(2):305-14.

38. Rahman M, Davis SR, Pumphrey JG, Bao J, Nau MM, Meltzer PS, Lipkowitz S. TRAIL induces apoptosis in triple-negative breast cancer cells with a mesenchymal phenotype. Breast Cancer Res Treat. 2009;113(2):217-30.

39. Amarante-Mendes GP, Griffith TS. Therapeutic applications of TRAIL receptor agonists in cancer and beyond. Pharmacol Ther. 2015;155:117-31.

40. Ruffion A, Al-Sakkaf KA, Brown BL, Eaton CL, Hamdy FC, Dobson PR. The survival effect of prolactin on PC3 prostate cancer cells. Eur Urol. 2003;43(3):301-8.

41. Perks CM, Keith AJ, Goodhew KL, Savage PB, Winters ZE, Holly JM. Prolactin acts as a potent survival factor for human breast cancer cell lines. $\mathrm{Br} J$ Cancer. 2004;91(2):305-11.

42. LaPensee EW, Ben-Jonathan N. Novel roles of prolactin and estrogens in breast cancer: resistance to chemotherapy. Endocr Relat Cancer. 2010;17(2):R91-107.

43. Joshi PA, Jackson HW, Beristain AG, Di Grappa MA, Mote PA, Clarke CL, Stingl J, Waterhouse PD, Khokha R. Progesterone induces adult mammary stem cell expansion. Nature. 2010;465(7299):803-7.

44. Beleut M, Rajaram RD, Caikovski M, Ayyanan A, Germano D, Choi Y, Schneider P, Brisken C. Two distinct mechanisms underlie progesterone-induced proliferation in the mammary gland. Proc Natl Acad Sci U S A. 2010;107(7):2989-94.

45. Mukherjee A, Soyal SM, Li J, Ying Y, He B, DeMayo FJ, Lydon JP. Targeting RANKL to a specific subset of murine mammary epithelial cells induces ordered branching morphogenesis and alveologenesis in the absence of progesterone receptor expression. FASEB J. 2010;24(11):4408-19.

46. Fata JE, Kong YY, Li J, Sasaki T, Irie-Sasaki J, Moorehead RA, Elliott R, Scully S, Voura EB, Lacey $\mathrm{DL}$, et al. The osteoclast differentiation factor osteoprotegerinligand is essential for mammary gland development. Cell. 2000;103(1):41-50.
47. Gonzalez-Suarez E, Jacob AP, Jones J, Miller R, Roudier-Meyer MP, Erwert R, Pinkas J, Branstetter D, Dougall WC. RANK ligand mediates progestininduced mammary epithelial proliferation and carcinogenesis. Nature. 2010; 468(7320):103-7.

48. Schramek D, Leibbrandt A, Sigl V, Kenner L, Pospisilik JA, Lee HJ, Hanada R, Joshi PA, Aliprantis A, Glimcher L, et al. Osteoclast differentiation factor RANKL controls development of progestin-driven mammary cancer. Nature. 2010;468(7320):98-102.

49. Tanos T, Sflomos G, Echeverria PC, Ayyanan A, Gutierrez M, Delaloye J-F, Raffoul W, Fiche M, Dougall W, Schneider P, et al. Progesterone/RANKL is a major regulatory axis in the human breast. Sci Transl Med. 2013:5(182):182ra155.

50. Anderson KN, Schwab RB, Martinez ME. Reproductive risk factors and breast cancer subtypes: a review of the literature. Breast Cancer Res Treat. 2014; 144(1):1-10.

51. Chlebowski RT, Kuller LH, Prentice RL, Stefanick ML, Manson JE, Gass M, Aragaki AK, Ockene JK, Lane DS, Sarto GE, et al. Breast cancer after use of estrogen plus progestin in postmenopausal women. N Engl J Med. 2009;360(6):573-87.

52. Beral V, Million Women Study Collaborators. Breast cancer and hormonereplacement therapy in the Million Women Study. Lancet. 2003;362(9382):419-27.

53. Hu H, Wang J, Gupta A, Shidfar A, Branstetter D, Lee O, Ivancic D, Sullivan M, Chatterton Jr RT, Dougall WC, et al. RANKL expression in normal and malignant breast tissue responds to progesterone and is up-regulated during the luteal phase. Breast Cancer Res Treat. 2014;146(3):515-23.

54. Wood CE, Branstetter D, Jacob AP, Cline JM, Register TC, Rohrbach K, Huang $L$, Borgerink H, Dougall WC. Progestin effects on cell proliferation pathways in the postmenopausal mammary gland. Breast Cancer Res. 2013;15.

55. Theoleyre S, Wittrant Y, Tat SK, Fortun Y, Redini F, Heymann D. The molecular triad OPG/RANK/RANKL: involvement in the orchestration of pathophysiological bone remodeling. Cytokine Growth Factor Rev. 2004;15(6):457-75.

56. Collin-Osdoby P, Rothe L, Anderson F, Nelson M, Maloney W, Osdoby P. Receptor activator of NF-kappa B and osteoprotegerin expression by human microvascular endothelial cells, regulation by inflammatory cytokines, and role in human osteoclastogenesis. J Biol Chem. 2001;276(23):20659-72.

57. Olesen $P$, Ledet T, Rasmussen LM. Arterial osteoprotegerin: increased amounts in diabetes and modifiable synthesis from vascular smooth muscle cells by insulin and TNF-alpha. Diabetologia. 2005;48(3):561-8.

58. Trouvin AP, Goeb V. Receptor activator of nuclear factor-kappaB ligand and osteoprotegerin: maintaining the balance to prevent bone loss. Clin Interv Aging. 2010;5:345-54.

59. Mrak E, Villa I, Lanzi R, Losa M, Guidobono F, Rubinacci A. Growth hormone stimulates osteoprotegerin expression and secretion in human osteoblastlike cells. J Endocrinol. 2007;192(3):639-45.

60. Rogers A, Saleh G, Hannon RA, Greenfield D, Eastell R. Circulating estradiol and osteoprotegerin as determinants of bone turnover and bone density in postmenopausal women. J Clin Endocrinol Metab. 2002;87(10):4470-5.

61. Shimizu M, Onoe Y, Mikumo M, Miyabara Y, Kuroda T, Yoshikata R, Ishitani K, Okano $\mathrm{H}$, Ohta $\mathrm{H}$. Variations in circulating osteoprotegerin and soluble RANKL during diurnal and menstrual cycles in young women. Horm Res. 2009;71(5):285-9.

62. Shinkov AD, Borissova AM, Kovatcheva RD, Atanassova IB, Vlahov JD, Dakovska LN. Age and menopausal status affect osteoprotegerin and osteocalcin levels in women differently, irrespective of thyroid function. Clin Med Insights Endocrinol Diabetes. 2014;7:19-24.

63. Khosla S, Arrighi HM, Melton LJ, Atkinson EJ, O'Fallon WM, Dunstan C, Riggs BL. Correlates of osteoprotegerin levels in women and men. Osteoporos Int. 2002;13(5):394-9.

64. Han KO, Choi JT, Choi HA, Moon IG, Yim CH, Park WK, Yoon HK, Han IK. The changes in circulating osteoprotegerin after hormone therapy in postmenopausal women and their relationship with oestrogen responsiveness on bone. Clin Endocrinol (Oxf). 2005;62(3):349-53.

65. Rahnama M, Jastrzębska-Jamrogiewicz I, Jamrogiewicz R. Influence of hormone replacement therapy on osteoprotegerin and receptor activator of nuclear factor kappa-B ligand concentrations in menopausal women. J Interf Cytokine Res. 2013;33(9):485-92.

66. Samelson EJ, Broe KE, Demissie S, Beck TJ, Karasik D, Kathiresan S, Kiel DP. Increased plasma osteoprotegerin concentrations are associated with indices of bone strength of the hip. J Clin Endocrinol Metab. 2008;93(5):1789-95.

67. Nolan E, Vaillant F, Branstetter D, Pal B, Giner G, Whitehead L, Lok SW, Mann $G B$, Kathleen Cuningham Foundation Consortium for Research into Familial Breast C, Rohrbach K, et al. RANK ligand as a potential target for breast cancer prevention in BRCA1-mutation carriers. Nat Med. 2016;22:933-9. 